\title{
Flexibility in manufacturing enterprises
}

\author{
N VISWANADHAM and N R SRINIVASA RAGHAVAN \\ Computer Science and Automation, Indian Institute of Science, Bangalore \\ 560012 , India \\ e-mail: [vishu,raghavan]@csa.iisc.ernet.in
}

\begin{abstract}
A manufacturing enterprise is a collection of interrelated, flexible, optimized business processes delivering value to the customers through high quality products and services, faster than competition. This view of an enterprise enables one to consider the entire business system including the suppliers, product development, manufacturing, logistics, distribution, and retailing and to smoothen out the interfaces between them. Performance measures and performance measurement are important for monitoring, control and management. We identify and discuss eight performance measures for generic business processes. These include lead time, customer service, dependability, quality, flexibility, cost, capacity, and asset utilization.

In this paper, we concentrate on flexibility of business processes with special emphasis on the supply chain and order-to-delivery processes. We attempt to provide clear definitions and measures of various types of flexibilities as well as discuss the relationship between product structure and supply chain flexibility. The relationship between uncertainties, flexibility, technology, and product structure is clearly brought out in this paper.
\end{abstract}

Keywords. Manufacturing enterprise; performance measures; flexibility.

\section{Introduction}

It is commonly believed that there will be dramatic changes in the ways successful manufacturing companies are organized in the 21 st century. These changes are basically driven by technological innovations, changes in political landscape, and demographics. In the developed world, electronic commerce has proliferated, and the information superhighway has made access to video connection and text-based information easy and almost free. Organizational structures, accounting practices, trading methods, compensation and incentive schemes that were so successful in the decades after World War II have become obsolete. In an earlier report (Viswanadham 1996), we have delineated issues that make manufacturing play a proactive role in inventing new businesses and organizational structures that give sustainable competitive advantage. 
Manufacturing has gone through successive periods of great changes. New materials, such as plastics, ceramics and composites, new technologies such as computer-aided design, manufacture and inspection, and the internet, new techniques such as kanban and just-in-time, new bases for competition such as cost, quality, time or core competence have all been at the root of these changes. Currently, global competition, demanding customers, liberalization which provides a congenial environment for direct foreign investment, regulations on environment, emergence of common markets, disintegration of large states, and volatile exchange markets have made manufacturing a more complex function. Customers want it all: low cost, low defect rates, high performance, on-the-spot delivery and maintenance without irritants. To meet such demanding customer needs, computer-aided automation, effective flexibility management, strategic alliances, management of end-toend processes such as supply-chain process, new product development process etc., are important.

This paper is organized as follows: In $\S 2$, we survey the history of manufacturing emphasizing the paradigm shift from mass production to mass customization. In $\S 3$, we describe the cosmic view of a manufacturing system including suppliers, distributors, employees, technology, competition and customers. In $\S 4$, we define a manufacturing system as a collection of business processes and consider issues of analysis using this approach.

In $\S 5$, we describe the supply-chain process and the order-to-delivery process which are two important customer value delivery processes in a manufacturing company. In $\S 6$, we identify eight performance measures for a business process. Section 7 is on flexibility of business processes. Since flexibility is the effective management of change, it is essential to conduct root cause analysis of changes and find ways of neutralizing or coping with the changes. We define business process flexibility in general and discuss the influence of technology on flexibility. We bring out the importance of information-sharing and communication in enhancing the flexibility of business processes. In $\S 8$, we present the definitions of various flexibilities of the supply-chain and the order-to-delivery processes. Product structure is the subject matter of $\S 9$ illustrating the influence of product modularity on staged manufacturing and the supply chain. We conclude the paper in $\S 10$.

\section{History of manufacturing}

Manufacturing, the world over, has undergone tremendous changes. Several companies in the West have gone through the phases of high growth, decline, restructuring, steady growth and so on. Several revolutions have occurred in the manufacturing arena: justin-time, total quality management, time compression etc. In this section, we survey the history of manufacturing with emphasis on changes in factors driving the competition and changes in organization structure.

\subsection{Mass production system}

In the early twentieth century, Henry Ford revolutionized manufacturing with the introduction of the transfer line for mass production. Complete and consistent interchangeability 
of parts and their assembly on a moving, continuous assembly line gave Ford tremendous advantages over competitors. Specialization and division of labour were the key concepts based on which both blue and white collar jobs were organized. Unskilled labour were trained quickly and supervisors, industrial engineers and quality inspectors ensured consistency and accuracy. The white collar jobs (so-called back-office work), were also broken down into small, repeatable tasks which were mechanized and automated. F W Taylor invented the principle of scientific management which made work more specialized, precisely defined, interchangeable and optimized. Alfred Sloan as the President of General Motors was responsible for developing the easily scalable, pyramidal organizational structure by creating decentralized divisions managed by specialists and coordinated by corporate headquarters. The mass production system was thus born and the fathers were Ford, Sloan, and Taylor (Womack et al 1990).

The mass production system is characterized by assumptions of constancy and predictability of demand, and the logic of economies of scale and division of labour. The characteristics of such factories include: dedicated machines, long production runs, narrow product range, low skilled workers, command and control management, vertical internal communication, high volume, sequential product development, high inventories, make to stock, limited communication with the customer, large number of suppliers and dealers, mass marketing etc. This mass production paradigm has influenced generations of industrialists and has generated wealth for western nations for over four decades. Also, we can see that stable, homogeneous markets and standardized products with long life, dedicated mass production facilities, command and control organization structure, low skilled labour, and long production runs, are all mutually reinforcing (Milgrom \& Roberts 1990).

\subsection{Modern manufacturing system}

The face of manufacturing has changed. Dedicated equipment is replaced by flexible machine tools and programmable multitasking production equipment (Viswanadham \& Narahari 1992). Their use reduced changeover times and small batch size production became economical. Small batch sizes shortened production cycles and reduced work-inprocess and finished goods inventories. Advances in computers and communications made possible direct contact with customers, suppliers and dealers. Rapid transport and communications resulted in global competition. This has created customers who make relentless demands in quality, service and price contrasting with the gentle, grateful, loyal customers of Ford and Sloan. Toyota, under the leadership of Ohno and Toyoda perfected the lean manufacturing system with emphasis on just-in-time deliveries, quality, and planning production and product development jointly with suppliers and dealers. Manufacturers now use the point of sale information to determine the production schedules. There is a general strategic emphasis on speeding up all aspects of a firm's operations: Shorter development cycles, quicker order processing, freedom from defects and speedier delivery. Make-toorder and almost instantaneous delivery have become more the rule than the exception. Frequent product improvements and new product introductions, combined with the need for speed have resulted in the use of cross functional teams for design and manufacturing.

We see thus that Adam Smith's world has changed considerably. Companies created to thrive on the mass production paradigm cannot succeed in the world of fast changing 
customer demands, short product life cycles, changing technologies, fierce competition and fluctuating exchange rates.

\subsection{Competitions based on cost, quality, time and customer focus}

Lean production or Toyota production system has introduced the concept of waste elimination by using just-in-time production. Waste, defined as any non-value adding activity, such as storage, inventory, transport, inspection, setups, machine down time, repair etc. should either be eliminated or minimized. Toyota has relentlessly attacked all forms of waste; reduced setup times, given importance to 'doing it right first time', eliminated inventories, introduced kanbans to trigger production, and used load leveling methods to smoothen the work flow. Toyota's methods of cost reduction during the energy crisis years of the 70's made them leaders of world class manufacturing. Also the new concept of target costing i.e. price is not cost plus profit but cost is market price minus profit, has been introduced (Womack et al 1990).

The eighties have seen the total quality management (TQM) revolution spreading from Japan to the West. TQM strives for a totally integrated effort towards continuous improvement at every level of the company: Design, production, marketing and sales. The ultimate beneficiary of TQM activity is the customer who receives high quality products/service at a reasonable cost. TQM involves process control rather than product testing. The aim is to produce zero-defect products through statistical process control and coordinated testing at input, production and final delivery points. Company-wide education and training, management commitment to design and implementation of an effective quality, performance measurement and reward system are essential for the success of TQM programs (Smith 1993).

Flexible automation involving numerically controlled machines connected by an automated material handling system and local area networks was the next important development. Computer-aided design and manufacture has made possible production of a variety of products at mass production economies. Consistent quality and manufacturing flexibility are two distinguishing features of factory automation. Together with factory automation, production planning and control systems such as MRP-II also emerged. The MRP-II system includes bill of materials, production plans and schedules, shop-floor control, inventory analysis, forecasting, purchasing, order processing, cost accounting, capacity planning etc. at various levels of detail (Viswanadham \& Narahari 1992).

Time-based competition is the issue occupying the minds of manufacturing executives even today. Customers want it all: price, quality and faster delivery, and hence firms must shrink the time from conception to consumption. Time reduction provides an important leverage not available in cost-reduction strategies. By removing time from their operations, costs are reduced. In manufacturing industries, time compression requires that attention be given to all activities including order processing, scheduling, distribution and customer service, i.e. time compression should include all activities not just on a single production function. On an average, a product spends only 2-10\% of the time and 20-30\% of cost in manufacturing, and the rest of the cost and time goes into other functions. Time-based competitors concentrate on the strategic business processes such as the order-to-delivery process and remove all non-value adding activities and compress time (Stalk \& Hout 1990). 
A new way of organizing businesses based on core competences is emerging in contrast to the product-centric view currently held by most companies (Prahlad \& Hamel 1990). Here, businesses nurture a bundle of competences by developing skills, capabilities, which in turn allow the company to market a group of world class products. Core competences developed over time by integrating the skills and resources in an organization will give the company a sustainable competitive advantage. Honda's knowhow in engines; logistics and inventory management of Federal Express; Sharp's competence in flat-screen displays etc., have allowed these companies to manufacture a variety of products/services which appear diverse. Many companies are turning to the competence-centric view and are disinvesting in the non-core sectors of their businesses.

We thus see that the logic of modern manufacturing is rooted in time and competencebased competition, flexibility and scope economies. Over the last decade a paradigm of mass customization has emerged with features such as flexible machines, short production runs, frequent new product introductions, niche markets, highly skilled team workers, cross functional teams, low inventories, no defects, make to order, continuous learning, extensive communication with customers, empowerment and long-term trust-based relationship with suppliers. We thus see that, in order to survive in the new world, closely coordinated changes are to be made in a whole range of the firm's activities. Quick fixes such as buying a CNC machine centre, setting up e-mail facilities or buying CAD software tools or installing MRP-II will not help.

\section{The manufacturing system}

In this section, we present an integrated view of a manufacturing enterprise. Traditionally, manufacturing meant just the factory floor and during the 70's and 80's much effort spent around the world has aimed at improving technologies (FMS, CIM), practices (JIT, TQM), and effectiveness.

In this paper, a manufacturing system means the entire enterprise and consists of several interconnected subsystems, all of which have to act in cohesion so that customer-desired products are delivered on time. The subsystems include (see figure 1).

(i) Suppliers: They provide the subassemblies, components or raw materials just-in-time to the factory floor and play a critical role. Their flexibility, agility, defect control and organization structure should all be compatible with the goals, objectives and vision of the manufacturing system. For example, suppliers of companies introducing new products frequently, should also have similar capabilities. Having only a few loyal suppliers and effectively communicating to them the product and process designs are some of the new successful practices that Japanese firms have taught the rest of the world.

(ii) Product development: Being fast enough to be the first in the market with the right product, is worth more to the prosperity of most businesses than any other single manufacturing function. Aggressive global competition, emergence of new technologies, opportunities for high value quality of life products, and legislative and environmental requirements, are some of the drivers for new product development. Concurrent engineering, integrated product-process design, multi-functional teams, 
and incorporation of customer voice, are some of the enabling solutions for effective product development

(iii) Factory floor: A flexible low-inertia factory, responding quickly to design and demand changes of the existing products and also to the need to produce new products, is mandatory. The layout, machines, work force and instrumentation and control hardware and software, are important elements of the factory floor. Recent trends include flexible manufacturing systems under computer control using client server architecture and agent-based scheduling strategies. Production planning and control strategies such as MRP-II also reside in the factory host computer.

(iv) Integrated logistics: Rapid response logistics to store and move raw materials, components, work-in-progress (WIP) and finished goods throughout the manufacturing system is another prime component of the manufacturing system. To maintain justin-time deliveries, on time, to globally distributed customers and to make-to-order final products from subassemblies produced in several geographic locations, an agile logistic system that is mix-and volume-flexible, is essential.

(v) Distributors: The ultimate customer is served through the distributors and they play a crucial role in selling the product to the customer. They can also provide feedback on customer voice and their expectations. Direct marketing, telesales, contracts between distributors and manufacturers, outsourcing and strategic alliances are some of the issues here.

(vi) Customers: They are the ultimate users of products and services and receive the final output and generate revenue. Incorporating customer voice into the designs, delighting the customers with no irritants in the purchase and use of the products, gearing the organization towards delivering value to the customers, analyzing customers complaints and defections and fixing the process, are mandatory exercises.

(vii) Organization structure: Design of a highly responsive organization structure through which information and decisions flow through very quickly, manned by people who make decisions and effectively communicate among themselves and with other stake holders, is critical for success. The tendency nowadays is to replace the traditional bureaucratic organizational structure with team-based flat structures. Management of end-to-end customer business processes such as order-to-delivery, new product and process development, using multi-functional teams headed by process owner and aided by software agents is also a popular paradigm.

(viii) Competition: Staying close to competition, benchmarking their best practices, winning their core-customers are strategies for survival. Competitive intelligence is currently an art and involves inferring from publicly available data, the methods and practices that make a company number one.

(ix) Technology: This is the factor that pervades all the above subsystems. Successful manufacturing companies use advances in technology to introduce new products, to run the factories more efficiently and also to increase their customer reach. Electronics technology has had tremendous impact on the control, instrumentation and communication fields and also in the consumer electronics area. New materials technology can also give crucial competitive advantage. Information technology changes 


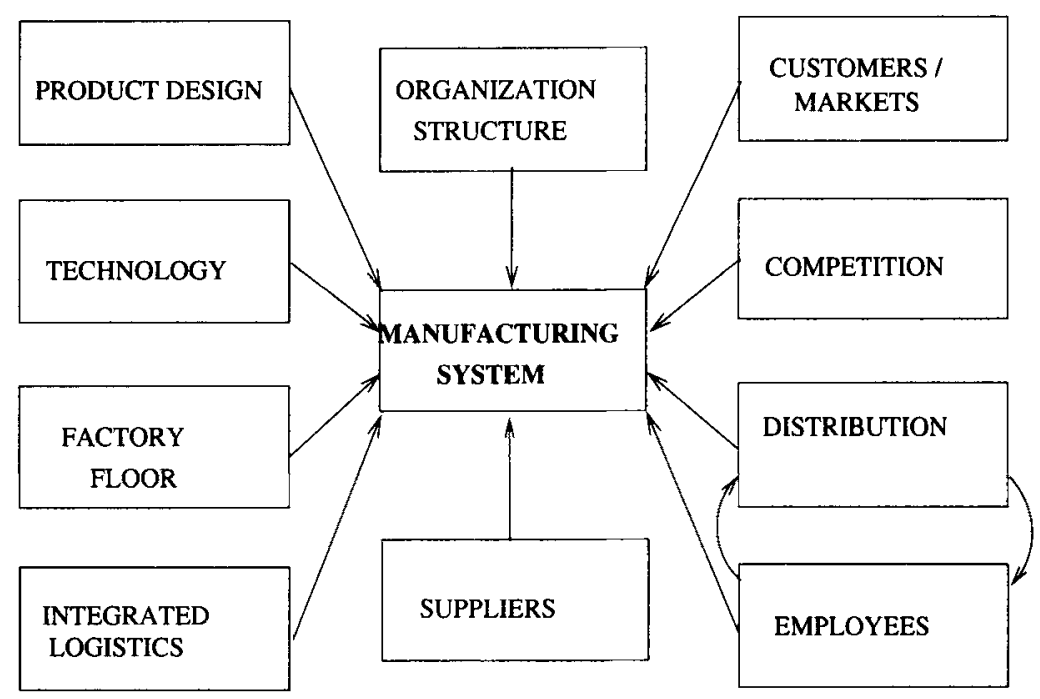

Figure 1. Competitive manufacturing as coordination of diverse skills and integration of multiple activities.

the way businesses are conducted (Venkataraman 1994). Internet, EDI, electronic funds transfer and e-mail have made several traditional systems obsolete. CAD systems have speeded up the design and retrieval process, and CIM has enabled flexible manufacture of high quality products. Managements should appreciate the value of technology and integrate it into their company's activities through effective use of R \& D (Upton \& McAfee 1996).

\section{The business process}

Traditionally manufacturing systems are viewed as a sequential arrangement of functions such as design, manufacture, $R \& D$, marketing, finance, and so on. The recent trend is to view a manufacturing system not in terms of functions, divisions or products, but as a collection of value-delivering processes. Functional or hierarchical structures typically present responsibilities and reporting relationships whereas process structure is a dynamic view of how the organization delivers value to the customer.

Hierarchical organization structures based on functional divisions have several problems. Each function acts as a silo and hands over its output over the wall to the next function. Turfwars, dominance by functions such as finance and marketing, result in slow progress of work through the system. Lack of proper communication between functions results in work going back and forth with long iteration periods (see figure 2). The hierarchical arrangements in the functions require that decisions are to be sought from the top and work processes inch up and down the hierarchy ladder. Thus one finds that the ratio of cycle time to processing time is enormously large, most of it made of non-value adding moving, waiting or information-collection time.

In contrast, the process perspective is to view a manufacturing system as a collection of important business processes which deliver value to the customer and manage those using 


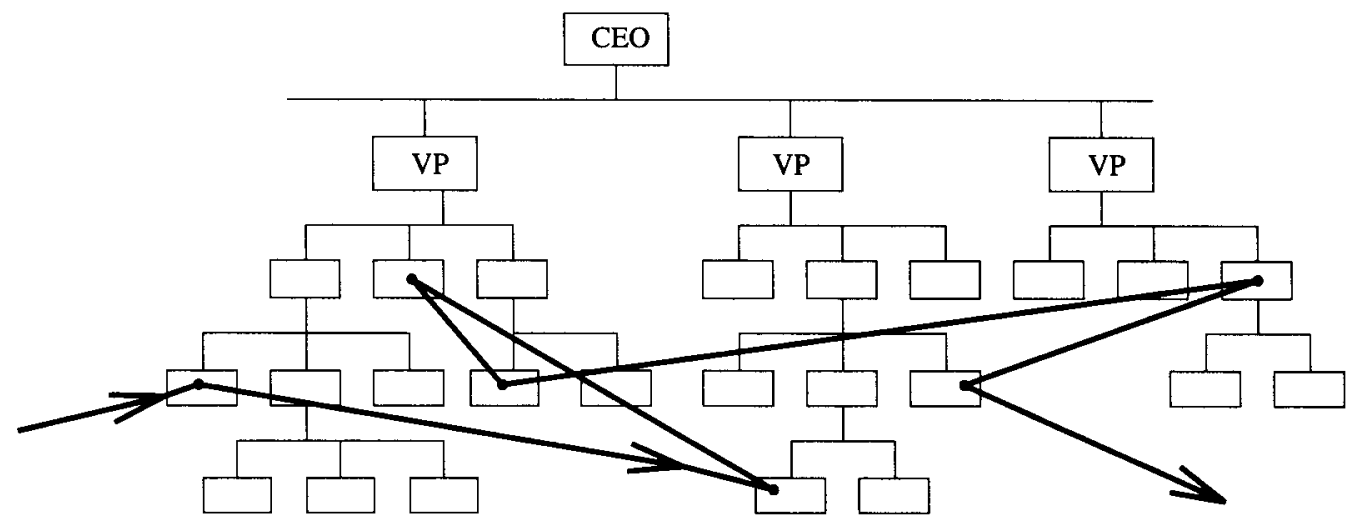

Figure 2. Work flow through a functional organization.

cross-functional teams in a coordinated manner (Davenport 1993). Process thinking originated with the quality movement wherein emphasis is on process control and team work rather than product inspection and command and control hierarchy. A process approach to business implies heavy emphasis on how work is done rather than focus on specific products (see figure 3 ).

\section{DEFINITION 1}

A process is a structured, measured set of activities ordered in time and space, designed to produce a customer-desired output.

Clearly, structured processes are amenable to measurement in a variety of dimensions: cycle time, defects, variability, flexibility etc. Examples of some typical processes include: order-delivery process, new product development process, supply chain process, factory floor process, maintenance process etc. A process perspective is a horizontal view of the manufacturing system that cuts across the organization with product inputs at the beginning

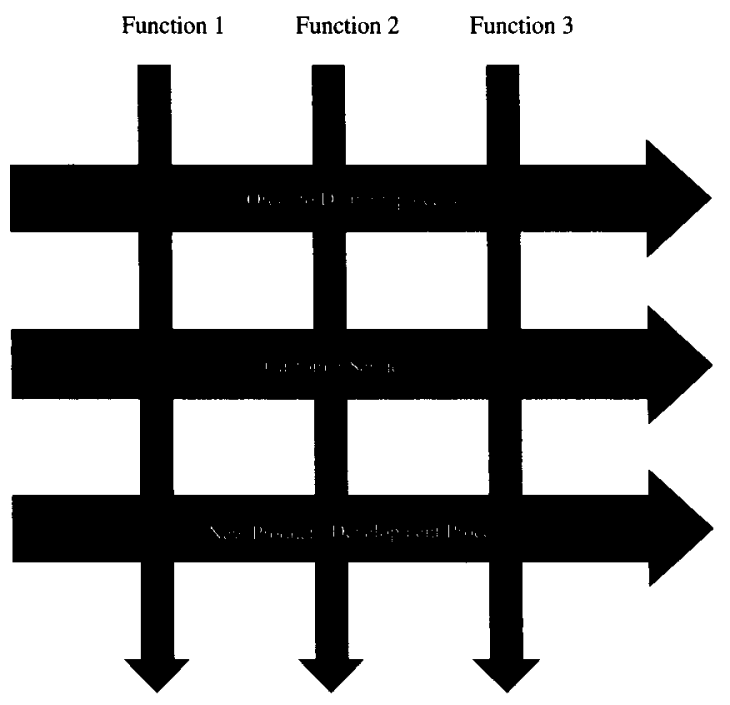

Figure 3. Functions and business processes. 


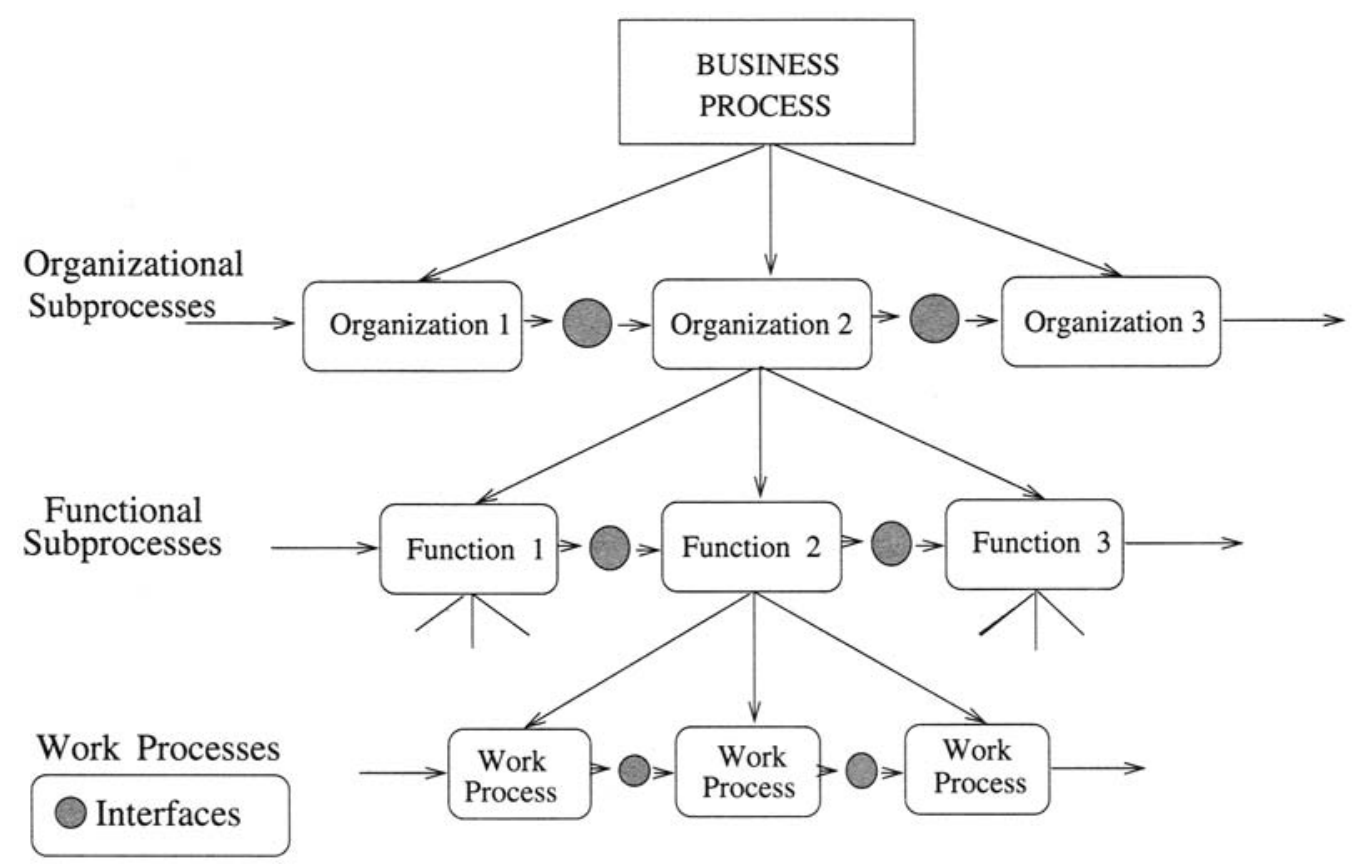

Figure 4. Business process hierarchy.

and customers at the end. Subscription to this view means deemphasizing the functional view of the business. The primary issue in vertical organization is the ill-management of hand-off between functions. Process orientation either eliminates hand-offs or coordinates them effectively. Processes are typically cross-functional.

There are several ways of decomposing a business process. We find it useful to decompose it into various subprocesses and work processes as shown in figure 4 . There are four different types of sub-processes in a business process. They are the following.

(1) Work process: This is a value adding activity with well-defined inputs and outputs with someone responsible for it. Examples include machining by a machine centre, transportation from one location to another by a truck, bill processing by a clerk etc.

(2) Interface between work processes: Interfaces are white spaces between work processes and interface management involves documented procedures for transfer of work from one work process to another. Some of the procedures may involve automated transfer of the workpiece from one machine to another. Generally, work processes may be within the same function and hence management may not be difficult.

(3) Functional interfaces: These are the procedures to be followed when the output of a work process in a given function in an organization is transferred to another in a different function in the same organization. Interfaces between design, manufacturing, marketing etc., come under this category. These are smoothened out by using crossfunctional teams to manage the subprocess in the organization and also by putting a measurement system in place that gives more weightage to the contributions made to the process by individuals and functions. One of the biggest achievements of process 
orientation is recognizing the problems associated with functional interfaces and evolving procedures for managing them.

(4) Organizational interfaces: These are again relationships, procedures and activities performed when a process transits from one organization to another. Examples include supplier-manufacturer, manufacturer-distributor-retailer, distributor-customer relationships. Here again through certification and alliances one can smoothen the interfaces and avoid all non-value adding and time-consuming activities such as selecting the suppliers through quotation, redundant activities such as incoming inspection by customers and outgoing inspection by suppliers, financial guarantees, multi-sourcing for reliability reasons etc. Through partnerships one can avoid overhead costs as well as smoothen the workflow.

Generally, functional and organizational interfaces are unmanaged or managed infrequently by higher levels of management. The management procedures, when they exist, are outdated. The prescription is to treat the interfaces also as work processes, with an ownership, well-defined inputs and outputs, and monitor their performance through appropriate measures. The goal is to smoothen the workflow and make it as continuous as possible.

\section{Supply-chain and order-to-delivery processes}

Supply chain process and the order-to-delivery processes are the most important business processes of a company and directly involve the customer. ODP starts with the arrival of an order from the customer and ends with the use of the product by the customer. In fact, some companies consider after sales support, and the return and recycling of the used product also as a part of the order-to-delivery process.

\subsection{Supply-chain process}

\section{DEFINITION 2}

Supply-chain process (SCP) encompasses the full range of intra-company and intercompany activities beginning with raw material procurement by independent suppliers, through manufacturing and distribution, and concluding with successful delivery of the product to the retailer or at times to the customer (Cohen \& Lee 1988).

Supply-chain management is the coordination of the supply-chain process, i.e. integration of the activities/subprocesses involved in procuring, producing, delivering and maintaining products/services to the customer who are located in geographically different places (see figure 5).

Long term issues in SCP involve location of production, and inventory facilities, choice of alliance partners such as the suppliers, distributors, and the logistics chain. The long term decisions also include make-to-order or make-to-stock policies, degree of vertical integration, capacity decisions of various plants, amount of flexibility in each of the subsystems etc. (Connors et al 1995). 


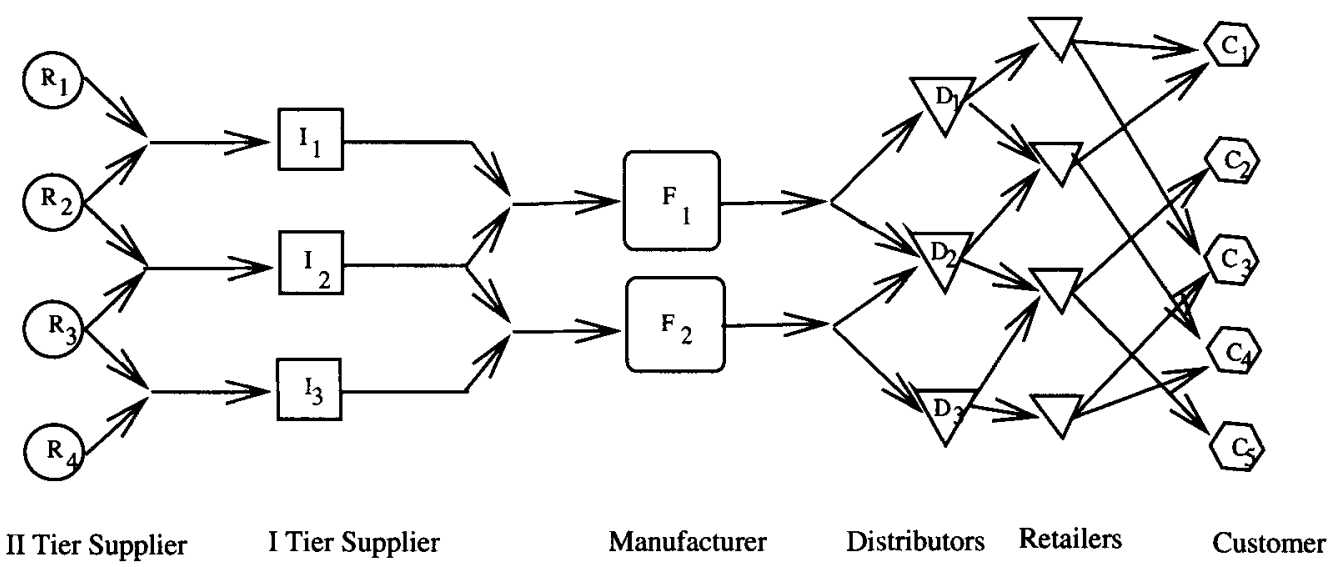

Figure 5. The supply-chain network.

The operational issues in SCP are the ones we are more concerned with here. They include cycle time, on-time delivery, cost effectiveness, flexibility and quality. Identification of customers and triggers for their loyalties (cost, after sales service, on-time delivery) are also to be assessed.

\subsection{Order-to-delivery process}

\section{DEFINITION 3}

The order to delivery process consists of six steps starting from accepting orders through order configuration, sourcing the order, managing the order, monitoring and finally billing and cashing.

We briefly describe each of these functions below (see figure 6).

(1) Accept orders: Customers choose many ordering methods and most companies accept orders through traditional means like fax, mail or through sales representatives or through EDI, telemarketing or direct marketing channels. Orders can also be placed on the internet, provided the necessary infrastructure is available. Customers can then track the order on the internet. The order information should be visible to all members of the supply chain. One important issue in this step is order selection and prioritization. All orders need not be accepted and not all customers are equal. It is known that $80 \%$ of the orders come from $20 \%$ of the customers for $20 \%$ of the products. These customers should be treated as "sweet spots" and given priority.

In this step, we have four tasks,

(a) Order receipt.

(b) Order selection.

(c) Credit check: Previous customers are checked for default; new customers are checked for credit rating. A rule-based expert system can suggest credit limits. Any exceptions that may arise are handled manually. 
STAGE 1

STAGE 2 STAGE 3
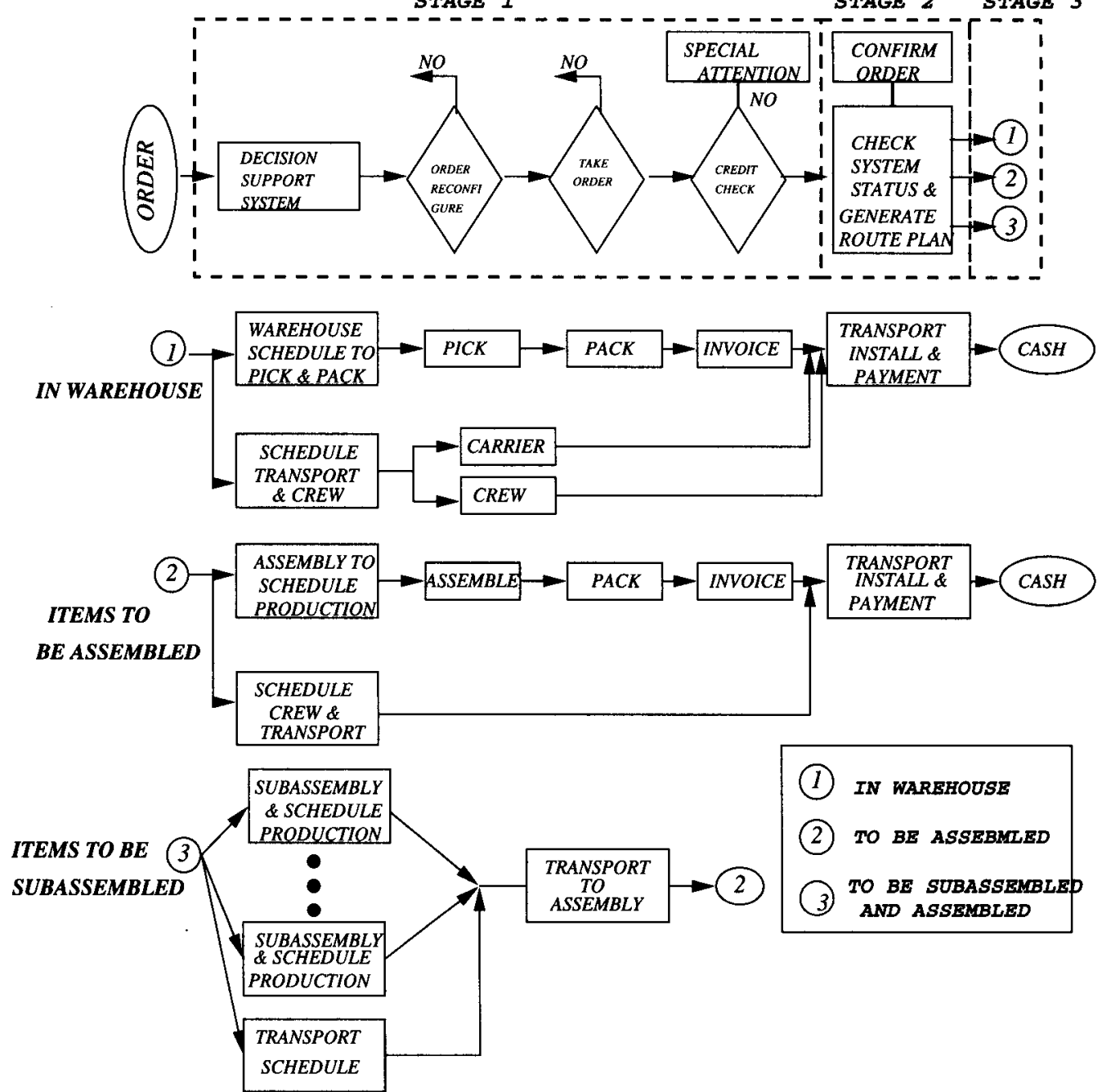

Figure 6. Order-to-delivery flow.

(d) Order confirmation: This involves the following.

- Check warehouse inventory and the allocation to current orders and back orders at all warehouse locations and determine if the current order can be met from nearby warehouses.

- Check the production orders in various plants.

- Make a decision on how the items from the order are to be shipped to the customer.

- Estimate cost and time.

- Dialogue with the customer on cost, delivery date and site planning if it involves equipment installations etc.

- Confirm the order, price and delivery date and time to the customer.

Figure 7 describes the controller interconnections that would enable the above functions to be performed. 


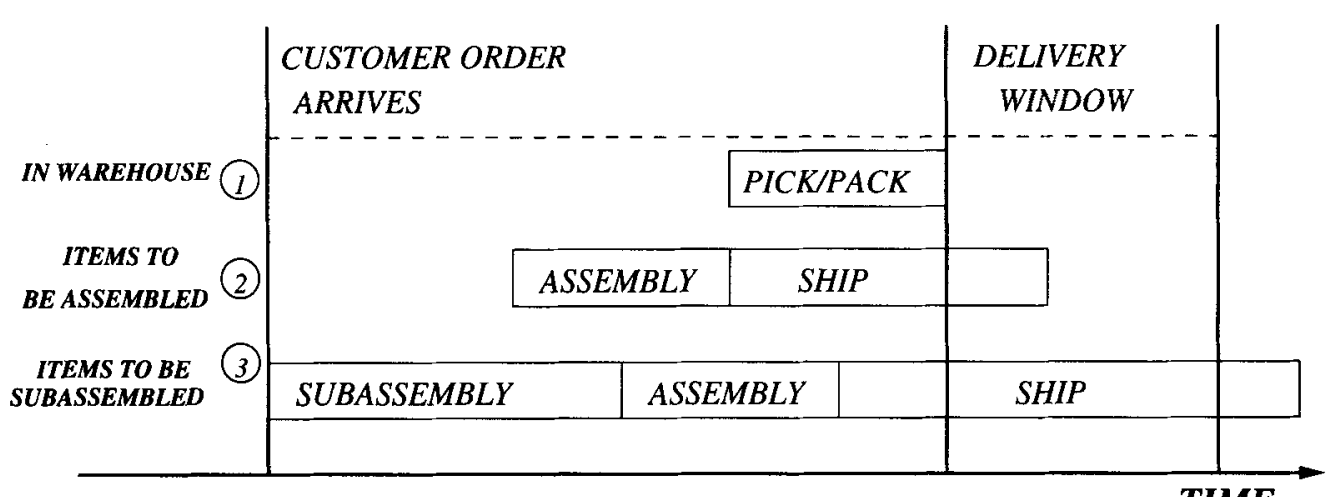

TIME

Figure 7. Delivery times for the three situations.

(2) Configure order: This consists of the following steps.

(a) Identify the complete list of products and services that are contained in the order.

(b) Plan and source each product and service in the order.

(c) Synchronize delivery of each of the items with availability of service personnel and transport as well as the convenience of the customer.

(3) Source the order: If the order can be met from a nearby warehouse, then all activities relating to picking and packing are initiated. If the delivery time allows, orders may be sourced from a nearby manufacturing assembly plant by passing the local distribution. In this case, the order is included in the production schedule. If the plant does not have preassembled subassemblies, then they are sourced from assembly suppliers and is assembled and sent directly to the customer. The idea is to supply the order within the delivery window (see figure 7).

(4) Order management: This is the final step and involves the steps outlined below.

(a) Making plans for coordinated delivery of the product to the customer.

(b) Customer's order execution plan is communicated to each member in the supply chain responsible for shipping the product or providing a service such as transportation or installation. Planning for transportation can start before shipment is ready.

(5) Order monitoring: Like in project management, the progress of the order is monitored and actual progress is compared with the anticipated progress. The signals of completion or failure are sent to appropriate agencies which automatically monitor the progress.

(6) Billing and cashing: Invoices are certified after installation of equipment and payment authorized to customer's accounts payable, who transfers funds via EFT to company's accounts' receivable.

The above ODP can be automated using EDI, bar coding, decision support systems and other IT tools to achieve rapid cycle times and high customer satisfaction (figure 8). 


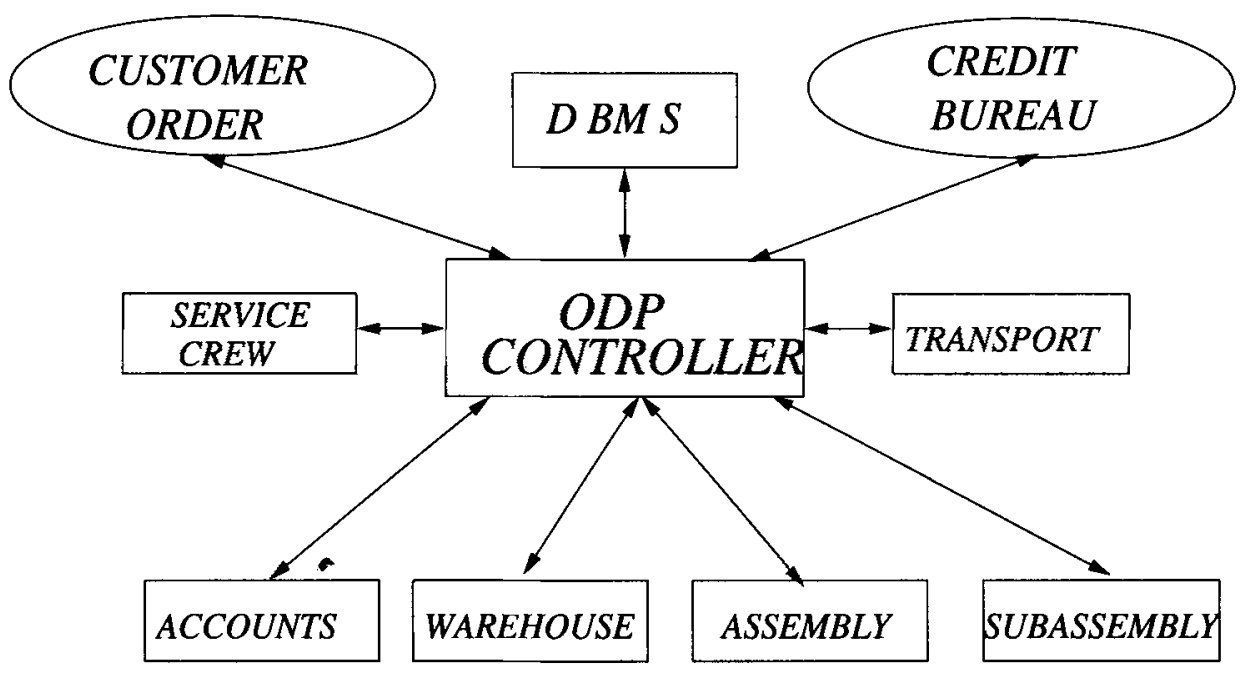

Figure 8. ODP controller.

\section{Performance analysis: A process approach}

Traditional performance analysis of manufacturing enterprises assumes that the enterprise is weakly coupled, i.e., the subsystems work almost independently. Paper-based communication, high inventories and arm-length relationships with suppliers, distributors and other stake holders justified this assumption. Performance analysis and optimization are conducted for individual subsystems and near-optimal performance of the total system was obtained by summing up the results. Each company is happy with its own operational and financial measures. Each function concentrates on and optimizes its own measures: sales on orders, manufacturing on throughput, distribution on shipments that maximize the truck utilization etc. This could result in sub-optimization at the overall systems and delayed customer deliveries. Products are designed for ease of manufacturing (DFM) and in assembly (DFA) and so on, but without worrying about logistic costs, import duty tariffs etc. In the name of reducing inventory costs, companies push the inventory either upstream to suppliers or downstream to distributors. Little do they realize that although they may have made cost reduction in the short term, the entire supply chain cost i.e., cost to the customer is the same or higher. Several intermediate manufacturers (e.g. automobile part suppliers) have to maintain lots of inventory because their customers (Original Equipment Manufacturers) have erratic ordering pattern, bad scheduling etc.; their suppliers are unreliable and are not quality conscious. Although they are lean and mean in their operations, they become heavy to keep the company efficient. Individual subsystem optimization is thus leading to total system suboptimization.

Our thesis here is that a process-oriented approach to performance analysis and optimization is the correct one and all the ills mentioned above can be eliminated. Furthermore, demanding customers and global competition dictate that the entire chain, i.e., the supply chain or the order-to-delivery process should be effective and not just a link like manufacturing or marketing. In fact, future competition will be process based and it will be 
the supply chain versus supply chain or new product development versus new product development, strategy versus strategy, etc.

Also, present day manufacturing systems are strongly coupled, both in terms of material and information flows. All stake holders in the manufacturing enterprises are connected via internet and intranet and also share a common database. Inventories are made very low and customers (both internal and external) insist on just-in-time deliveries. Further, suppliers, distributors and customers have a fundamentally different and cooperative relationship called partnership for sharing information, finances and helping one another in resolving quality and technology problems. Decisions in location of various facilities, manufacturing plants, distribution centres etc. are now taken by considering all costs: supplier-manufacturing, customer-manufacturing, distribution, transportation and other infrastructure costs. One may find that typically manufacturing cost accounts for only $20-30 \%$ of the total cost. These changes make the enterprise strongly coupled and any analysis has to be conducted for the entire monolithic system.

As discussed earlier, we consider a manufacturing system as a bundle of business processes. The business processes are value delivery streams starting with a customer need and ending with customer satisfaction. We now define the performance measures for business processes. For ease of presentation, we target all results from now on for the order to delivery and supply chain processes. The important performance measures of business processes are the following.

(1) Lead time: The lead time of a business process is the interval between start and end of the process. It is the concept to market time in the case of the product development process and the clock time between placing an order to the delivery at the customer site in the case of ODP and start of raw material ordering till the final assembly reaching the retailer in case of the supply-chain process. Lead-time reduction by removing non-value adding activities, and effectively managing interfaces with suppliers, manufacturing, logistics and distributors is an important exercise.

(2) Customer service: Delivery of customer-desired products at the right time, in the right place and in the right quantities every time is the goal of customer service. Customers could be external customers (or end users) or internal customers.

(3) Dependability: This is the reliability of product delivery and is an operational issue. It measures the ability to manage disruptions, such as machine failures, worker absenteeism, truck failure or supplier failures, rush orders etc.

(4) Cost: Like the lead time, cost also provides rich insights into process problems and inefficiencies. Interface costs, margins, costs in negotiations, inspection etc. are a waste and provide avenues for cost-cutting strategies.

(5) Quality: Quality is management of all the work processes so that they are on target with low variation. This is achieved through root-cause analysis of defects and failures and elimination of the causes of failures.

(6) Flexibility: Ability to meet customer requirements under various environmental uncertainties in various dimensions such as delivery time, schedules, design and demand changes etc. Flexibility of business processes is closely related to product structure or task graph and also to technology. 
(7) Capacity: This is the total output rate of the business process. All the work processes are to be balanced in capacity otherwise there will be bottlenecks and delays. Strategic alliances are common among various work process owners since vertical integration is almost impossible. A little amount of over-capacity to meet rush demands would improve operational measures.

(8) Asset utilization: The assets in some business processes (like the supply chain process and the order-to-delivery process) such as manufacturing plants, warehouses, communications infrastructure, fleet of vehicles etc. are worth billions of dollars at times. Their utilization is an important issue.

One could define other measures such as the throughput of the business process and the work-in-progress along the process. Also, product variety supplied and defects in the process are important measures which could be inferred from the above. We deal only with flexibility in this paper.

\section{Flexibility}

\subsection{Anatomy of changes}

Literature defines flexibility as a system's capability to cope effectively with a wide range of environmental changes and internal variations without deterioration in system performance in terms of cost, quality, lead time and on-time delivery. It is certainly a desirable virtue to possess for a manufacturing system in these times of global competition, turbulent changes and mass customization. It is certainly not a new concept and has been studied in the economic and organizational context. Earlier studies in flexible manufacturing were emphasizing flexibility in the context of the factory floor (Upton \& McAfee 1994, 1995). In this section, in contrast, we are concerned with the flexibility of the entire business process.

Since a business process is an ordered set of work processes, it is essential that the work processes be flexible for the business process itself to be flexible. Flexibility enhances performance measures such as lead time, quality, and on-time delivery. It also allows the manufacturing system to cope with uncertainties such as those listed below.

(i) Resource changes: Variations in the number of human and machine resources on a factory floor due to machine failures, absenteeism etc; transport breakdown in the logistic system; a rush order from a valued customer; supplier bankruptcy etc. are issues that arise routinely. Process management should be able to cope with these kinds of change.

(ii) Design and demand changes in the product: The changes could be either planned or unplanned. Customer demand is random and this combined with inaccurate forecasting will cause uncertainty in the design and mix of products. Also, proactive introduction of new products to beat the competition will reflect as planned change.

(iii) Technology changes: These could be continuous or discontinuous. Discontinuous technology changes such as the ones in the PC industry and the hard disk drives are 
difficult to cope with. The company should have the ability to predict and develop competences in new technologies for future product generations and also have the capability to evaluate the risk associated with new ventures.

(iv) Socio-political changes: Deregulation of telecommunications, airlines, information networks etc. has a big impact on existing players. Liberalization of certain closed economies had the same impact. Legislations on health care had tremendous impact on hospital and health insurance systems.

\subsection{Coping with uncertainty}

We see that as we traverse from resource changes to design and demand changes in the product to socio-political changes, both the magnitude and the effect of change will increase. They can be classified as operational, tactical, and strategic changes and the flexibility strategies could be correspondingly named. The resource changes occur daily and appropriate procedures have to be designed and built into the system. Events such as failure of a machine or a truck or a rush order occur at random times and places. Procedures, like those in hospitals and civil defense, should be evolved for all frequently occurring events. Design and demand changes occur, say monthly, and they have to be met through proper scheduling of orders. They are tactical in nature and involve suppliers, logistics and distributors. The technology changes are sporadic but occur in a predictable way for companies with learning capabilities. Some companies see the opportunity and lead the change in an offensive way. They are strategic in nature and involve proactive strategies for product development, technology adaptation, etc. Socio-political changes are outside their control but some companies turn these into opportunities as well.

The flexibilities built into the enterprise should have the abilities to cope with these changes. These abilities are built into the enterprise via technology, procedures, control mechanisms such as scheduling, information processing etc. It is important to analyze the changes that a system is subjected to, so that appropriate flexibility strategies could be designed and implemented.

The best way to cope with uncertainty is to eliminate the sources of uncertainty. This may not always be possible but one can certainly reduce the amount of change. For example, customer surveys and monitoring point-of-sale information, redesigning product range to increase part-commonality and delaying final assembly until receipt of order, will reduce demand uncertainty; preventive maintenance, use of diagnostic expert systems, and builtin fault tolerance will reduce the down-time and increase the system availability; quick adoption of new technologies such as IT and their proper implementation will remove all non-value adding activities and cut costs and delivery time to a minimum. Then one can confidently face, in fact, lead price wars in the face of deregulation.

At times, it would help eliminate the need for change by replacing a rough terrain with a smooth road rather than trying to cope with it. By providing a smooth road, and a constant environment for a vehicle, one avoided the need for flexible legs. By providing transfer mechanism in an automobile assembly, which can transfer the workpiece across machine tools, one has eliminated the need for sensory and manipulative human functions (Viswanadham \& Narahari 1992). 
Group technology cells, each focusing on a product family, streamlined the product flow on the factory floor thus eliminating the need for sophisticated material tracking and scheduling algorithms.

A flexible manufacturing enterprise whose business processes can cope with all the above changes will be extremely complex, expensive and time-consuming to install. It requires redundancy in terms of excess capacity, space and time which again will increase the cost of the products. In an environment of fast-changing technologies, shrinking product life cycles, and changing customer attitudes, one should strike a balance between cost and time for implementation and hedge against near-term uncertainties. One has to recognize that each industry/firm has only a finite life and eventually has to open new factories for new products and phase out old ones.

An analysis of the product line of the enterprise for the next five years using good forecasting techniques, is generally done to determine the uncertainty in demands and the appropriate manufacturing system (focused cellular manufacturing cells, flexible manufacturing system or flexible transfer line) is decided. The kind of flexibilities that are needed to meet the customer demand could also be determined at this stage. Methods such as strategic alliances, acquisitions, out-sourcing, subcontracting are used to augment the competences. Benchmarking is used to determine the best in class manufacturing practices and the performance gaps.

Thus we see that a preliminary analysis of the uncertainties will lead to an appropriate manufacturing system configuration which can effectively cope with their changes induced by them.

\subsection{Flexibility and technology}

Information and communication technologies such as EDI, EFT, CAD, FMS, ASRS, groupware, local area networking, bar coding, internet, intranet are extensively used to speed up the process as well as to deliver better value to the customer. Automation technologies such as FMS, ASRS, MHS are very expensive, others such as EDI and bar coding require process simplification and analysis before implementation. The communication technologies such as EDI, EFT etc. are integrative technologies and their added power comes from the fact that information collection, storage and processing could be done in real-time and transferred to all the stake holders. For example, order information, point of sale and inventory status could be monitored by all concerned such as distributors, manufacturers, suppliers etc. This information can be gainfully employed to schedule production based on the needs of the customer. Advantages and use of all the technologies mentioned above is well documented in the literature (Corline \& Essaides 1993; Hartley 1993).

All the core business processes such as the supply chain process, order-to-delivery process, new product development process, factory floor process and logistics process are all influenced by the above technologies to improve the cycle time, quality and enhance the delivery reliability (Hartley 1993). Quick changeovers, sharing of information (on customer order, product designs, inventory status, point of sale), supplier, logistics and distributor partnerships are enablers of high performance, low inventories and high flexibility (Corline \& Essaides 1993; Srinivasan et al 1994). Customer desired product variety can be supplied without penalty on performance (Kekre \& Srinivasan 1990). Low inventories result 
from quick transfer of information to all stake-holders. Empirical studies on performance improvement exist in the literature (Kekre \& Srinivasan 1990).

Several analytical studies have appeared in the literature on questions such as: whether to buy rigid or flexible technologies for a given demand forecast, economics and advantages of EDI, whether a supplier should adopt EDI, whether a customer should invest in a supplier's infrastructure (production technologies, EDI, etc) (Wang \& Seidmann 1995), vertical integration or virtual integration, whether a supplier should follow a leader model or follower model etc. (Srinivasan et al 1994; Wang \& Seidmann 1995).

Technology has made possible the sharing of various kinds of information and partnering. Virtual integration is an alternative to vertical integration and it provides flexibility to meet changing demands. In a changing scenario, whether to change the partnership or invest in enhancing the capabilities of existing suppliers is the big question. Much can be said on both sides. Also, choice of suppliers, distributors and transporters is an irreversible decision until the end of the contract. Changing the partners involves considerable time and effort and is comparable to the set-up time and cost. It is important to note that good partnerships will cut both cost and cycle time. A manufacturer can maintain the shelf space in a supermarket bearing the inventory, transportation and obsolescence costs in return for point-of-sale information (Venkataraman 1994). A distributor can maintain the inventory of hot spares and medical supplies to have big customers locked-in. Bennetton, Walmart, and Dupont have used technology to redesign their business processes for high flexibility in terms of response to customers and high performance in terms of low cycle times (Corline \& Essaides 1993; Hartley 1993).

\subsection{Flexibility in manufaturing enterprises}

It is common misunderstanding that flexibility is achieved through flexible machine or computer hardware acquisition. The truth is far from that. Indeed several companies incurred losses, let alone breaking even, because productivity reduced with introduction of new manufacturing hardware. Process variety complicates the parts supply and assembly process because more parts require a greater coordination to get the right part into the worker's hands at the exact instant the guided vehicle brings the car to the worker's station. Because of the complexity induced by variety, many companies view flexibility management as a necessary evil (Sethi \& Sethi 1990).

Manufacturing enterprises increasingly look like restaurant chains. Customers place their orders, waiters transmit the specification to the kitchen and a team of cooks assemble the product. The products are designed already and part programs are available, as soon as customers order from a table look-up, products are scheduled and delivered. This kind of flexibility is static flexibility or product-centric view of flexibility. On the other hand, dynamic flexibility is creation of capability to act in response to opportunities as they arise over time. Competences to developing new designs and new products to manufacturing customer desired products and to deliver them faster than competition are tenets of dynamic flexibility (Macduffie et al 1996).

There are four basic types of flexibility: mix, volume, new-product and delivery time flexibilities. See table 1. Each is important in a different environment (Suarez et al 1996). These flexibilities are implemented through a variety of factors such as production technology, 
Table 1. Types of flexibility.

\begin{tabular}{ll}
\hline Mix Flexibility & $\begin{array}{l}\text { Ability of a system to simultaneously produce a number of different } \\
\text { products in a given period. }\end{array}$ \\
Volume Flexibility & $\begin{array}{l}\text { Ability of a system to change significantly the production level and the } \\
\text { composition of the product mix in a short time span. }\end{array}$ \\
New Product Flexibility & $\begin{array}{l}\text { Ability of a system to add or substitute new products to the product mix } \\
\text { over time. }\end{array}$ \\
Delivery Time Flexibility & \begin{tabular}{l} 
Ability of a system to reduce the order-to-delivery time \\
\hline
\end{tabular}
\end{tabular}

product management techniques, relationship with suppliers and distributors, human resource management and product design. It is important to realize that different types of flexibilities are important in different competitive situations. For example, mix flexibility is important when a firm has a broad product line and caters to different market segments. There are several ways of achieving each type of flexibility. Mix flexibility may be achieved through skilled workers or programmable equipment. New product flexibility is needed in technology intensive markets. Volume flexibility is important in volatile markets.

Flexibility management is a competence that involves skillfully managing several resources of the system including automation hardware, software, people, organization structure, suppliers, customers, distribution channels, and factory floor control systems. It is an integrity-related competence and involves collective learning in the organization, coordinating diverse production skills and integrating multiple streams of technologies. It is a capability for deploying various resources of the company using the organizational processes to efficiently and economically produce a wide variety of part types. We elaborate this point with respect to the relationship with suppliers and distributors.

A formal relationship between suppliers and distributors is essential for a positively correlated flexibility productivity relationship. First, the capability of a manufacturer to offer a rich variety of products is dependent on the supplier's capability to produce a variety of component parts, i.e. the supplier's flexibility in several dimensions: delivery time, mix, volume and new products. If components for each product in the mix are sourced from different suppliers, then the management overhead increases enormously. Secondly, when a plant has machine failure problems or when there are sudden volume surges time-sensitive orders can be sub-contracted to dependable contractors.

The ability of the manufacturing system to produce a variety of products should be matched with the ability of the distributor to pass the variety on to the customer by proper advertising and maintaining appropriate inventory levels. Also, distributors by their close interaction with customers can easily identify their true needs and preferences so that the company can produce what sells rather than trying to sell what is produced, thus minimizing "market defects", i.e. producing things that customers do not want. One cannot underestimate the influence of distributors in variety management, both in information collection and also in sales. Further, the use of information technology tools such as electronic data interchange, electronic funds transfer and customer sales tracking systems by dealers and suppliers enhance the delivery time flexibility.

From the above discussion it is clear that flexibility needs to be defined, designed and created for end-to-end business processes. 


\section{Flexibility in business processes}

\section{DEFINITION 4}

A business process is flexible if it can effectively manage or react to change with little penalty in time, cost, quality, or performance.

This is of course a very general and abstract definition. Our discussion in this section will concentrate on issues concerning any business process; the specific concerns of new product development, supply chain and order-to-delivery process will be dealt with as examples. As we saw earlier, a business process is an ordered set of work processes and interfaces (both functional and organizational). The interfaces are generally managerial processes such as sharing information, rules and procedures etc., depending on relationships with suppliers, distributors, customers etc. Work processes typically involve tasks such as design, manufacturing, marketing, sales etc. It is essential that the interfaces are smoothened out and work processes are flexible for the entire business process to be flexible. Interfaces between functions and organizations are like setups which have to be reduced by continuous improvement.

Previous studies on flexibility have so far been confined to factory floor technology, setup times, WIP, and so on. The volume and mix flexibilities are defined with the factory floor in mind. Here we talk of the entire business process, as flexibility of some of these processes such as customer acquisition may not include the factory floor. Flexibility in human resources, infrastructure flexibility and flexible management structures are all examples of flexible processes beyond the factory floor.

Now we consider SCP and ODP and discuss flexibility issues in these processes.

\subsection{Supply chain process}

\section{DEFINITION 5}

A flexible supply chain process is one that responds effectively to changes in volume, product mix, delivery times and delivery routes without deterioration in cost, quality and lead time.

It is essential all subsystems be flexible for the supply chain process to be flexible. Flexibility management is a capability that has to be built up over time through the use of skilled work force, automated equipment, IT tools, computer control systems, bench marking and implementing the best practice and the like.

We will first discuss the various types of flexibilities for the supply chain. Essentially flexible supply chains accommodate special customer requirements, provide customized service, allow product modification while the order is in process, introduce new design features and so on.

\section{1a Volume flexibility in supply chain process:}

\section{DEFINITION 5.1}

A supply chain is volume flexible if a customer order with different product mixes and volume levels can be processed for rapid delivery. 
It is essential that small batches of products are produced and delivered for a system to be volume-flexible. This implies that setup times are small all along the process. This is because the economic batch size in any work process (manufacturing or transport) is an integral multiple of its successor.

\section{1b Mix flexibility in supply chain process:}

\section{DEFINITION 5.2}

A supply chain is mix flexible if the system can produce a number of products simultaneously and deliver them to the customers.

This capability indicates the breadth of the product line and ability for quick changeovers. The suppliers are either mix-flexible or there are more number of suppliers. Also warehouse and transportation should be able to handle different sizes, shapes and installation procedures (multi-skilled labour).

Excessive product variety induces several problems in both performance and management. The system complexity increases with a greater number of suppliers (at least two or more for each component), since establishing partnerships, sharing information, helping in quality control, reducing changeover times etc. are all time- and effort-consuming processes. Thus variety means more design, more production planning and control, and more forecasting and more leftovers. While no one can disagree that one should have variety, it is necessary to find and manufacture the twenty percent of the products that win in the market.

\section{1c Routing flexibility in supply chain process:}

\section{DEFINITION 5.3}

This is the ability of the supply chain to produce and deliver to the customer through alternate routes or, equivalently, each function (manufacturer, warehousing, transporting) could be performed in more than one location.

Routes to supply equipment or to fill in the order can be ordinarily fixed but can be changed in the event of problems such as breakdown. Routing flexibility is generally obtained by duplicating each function in various locations, having over-capacity and redundancy in transportation, and efficient scheduling and control software. The average number of possible ways in which an order can be filled could be used as a possible routing flexibility measure. For example, an order for a workstation from an Indian customer, can be filled either from Singapore or Europe or USA in a variety of routes. Depending on the time available, it is sent by air freight or by ship.

\section{1d Delivery time flexibility in supply chain process:}

\section{DEFINITION 5.4}

A supply chain process is delivery time flexible if it can reduce or expand the delivery time as per customer requirements. 
Here again, rush orders and delayed shipment requests are common from customers. Ability to reschedule the orders all along the supply chain, low variation of the lead times of all the work processes, quick change-over times, excess capacity in all resources, are some of the requirements for delivery time flexibility.

\section{1e New product flexibility in supply chain process:}

\section{DEFINITION 5.5}

A supply chain process is new product flexible if generations of several new products can be rapidly designed and marketed simultaneously.

This is a very important flexibility for most manufacturing companies. A cross-functional team with a process owner manages the product development process with reviews and testing at intermediate points in the process to maintain design quality. The team has members from among suppliers, distributors and at times even customers, apart from having functions within the organization, so that the designed products are manufacturable, saleable, and satisfy customer specifications. Time-to-market is critical for this process to gain the advantages of first mover (Ulrich \& Eppinger 1995). Patenting, navigating through regulatory agencies, production, marketing etc. augment product development capability. For example, pharmaceutical companies are most R \& D intensive and the high cost of drug production mandates introduction of the drug worldwide to make the most from the effort. Thus a company should not only have capability to innovate new drugs but also have downstream capabilities to navigate it through regulatory mechanisms, and for manufacturing, marketing, and distribution in domestic and foreign markets.

\subsection{Flexibility in order-to-delivery process}

We now consider the flexibilities connected with order-to-delivery process.

\section{DEFINITION 6}

An order-to-delivery process (ODP) is volume-flexible if a number of customer orders with different product mix and volume levels can be simultaneously processed for rapid delivery.

Mix, routing and delivery time flexibilities of an ODP can be similarly defined. Notice that volume flexibility of the ODP requires flexible order processing, and a flexible supply chain process with flexible manufacturing, logistics chain, marketing channels, etc. Also all these subsystems need not be within the boundary of a single firm, they could be part of a supplier-manufacturer-distributor value chain. For example, a catalog store has an ODP that is mix- and volume-flexible if it can reliably coordinate the supply chain. Similarly a car dealer is mix-flexible if he can arrange for delivery of any customer-desired car as quickly as possible. An ODP is routing-flexible if it has redundant suppliers, manufacturers, distribution etc. in various locations. Table 2 gives some measures of the flexibility for an ODP. 
Table 2. Flexibility measures for ODP.

\begin{tabular}{ll}
\hline Type & \multicolumn{1}{c}{ Measures } \\
\hline Mix flexibility & $\begin{array}{l}\text { Number of different products that can be supplied. } \\
\text { - Optimistic changeover times and costs among different products (function of } \\
\text { scheduling) }\end{array}$ \\
Volume flexibility & $\begin{array}{l}\text { - Stability of cost of delivery over varying levels of production volumes. } \\
\text { - Smallest profitable volumes of operation. }\end{array}$ \\
Routing flexibility & $\begin{array}{l}\text { - Average number of ways in which a product can be ordered, manufactured, } \\
\text { and delivered. }\end{array}$ \\
\hline
\end{tabular}

Three aspects of ODP flexibility - Flexibility is the response of a firm or a group of firms to uncertainty. We have identified three different types of changes: short-term, mid-term and long-term. Business processes and all systems involved in it have to manage these changes effectively. The built-in hardware, software and management procedures should be able to counter the variations or changes. We identify operational, tactical and strategic flexibilities in the ODP context.

8.2a Operational flexibility: Short-term changes occur very frequently, may be every few hours to every day. We assume that the organizational and functional interfaces are all smoothened out, i.e. coordination of deliveries with suppliers, collaborative arrangement for distribution, are all in place. A business process is operationally flexible if it permits a high degree of monitoring and control to accommodate short-term changes.

Basically operationally flexible firms have the list of possible contingencies that can occur or have previously occurred and a list of methods to deal with the situations. Like the emergence of procedures in civil, defence or medical fields, the approach taken can be reactive or for eliminating the root cause of the contingency. In either case the customer's problems are resolved. A firm should have the formal procedure in place to automatically accommodate routine or anticipated events occurring at random points in time, with staff empowered to make decisions. Encouraging creative response by staff will help in operational flexibility of processes such as ODP which are characterized by massive detail over a large geographical area. Use of outside service providers and strategic partners is also common. Some examples include:

(1) withdrawal of a the drug from the market because of possible contamination in a batch;

(2) failure of earth-moving equipment in a remote location, for which spares need to be delivered as soon as possible.

8.2b Tactical flexibility: An important characteristic of tactically flexible processes is the ability to switch quickly and cheaply between products. Real time data collection at point of sale, networked organization structure, EDI interconnection, bar coding etc. are important ingredients of the system. Good implementations include quick response manufacturing by Dupont and desktop publishing facilities by McGraw-Hill. Basically, in case of tactical flexibility, we are concerned with delivering known products to customers 
subject to the required delivery schedule (both in quantity and time). Reduced setup times and costs at various machines in the suppliers' and host's manufacturing plants, fast communications, say through EDI, among all stake-holders, reducing transport costs either by using small trucks or by sharing the truck among different suppliers, packaging products in a form directly usable by the customer, having surplus capacity in the manufacturing and transport systems to take care of breakdowns in machines and transport, fault-tolerant control system to manage the system, are some of the attributes of such systems. Benetton, TESCO, and Walmart are examples of successful tactically flexible order-to-delivery business processes. Similarly, custom-made book publishing by McGraw-Hill is also an example of tactical flexibility in various business processes. In all these cases the changes are in the demands of the customer. The response of the company or group of companies to provide the range of products has to be quick. This is achieved through strategic networking and communication of suppliers and customers in case of Benetton, TESCO and K-Mart.

8.2c Strategic flexibility: This involves development of competence in technologies to lead the industry in all work processes and innovation in managing/eliminating interfaces. It is concerned with the ability to make good use of undisclosed opportunities, either through the production process or the product. It is the ability to respond to unmeasurable changes in the market conditions and unprogrammed advances in technology.

Any type of flexibility arises from two sources: from assets (tangible or intangible objects useful in product delivery) and organization or coordination of these assets to gain competitive advantage. Strategic flexibility is the ability to deploy the assets and capabilities to create, produce and offer new products to markets in a changing environment, dynamic markets and shifting technologies.

\section{Product structure and flexibility in supply chains}

Performance and flexibility issues in supply chain and order-to-delivery processes are intimately related to the product structure and also to the logistics network organization. Modular designs with customization occurring as late as possible in the production are preferred. Also manufacturing facilities are staged with customization occurring with the help of local suppliers to meet local language, power, and communication standards. The combined product and logistic network design yields the following structures (Williams 1981; Macbeth \& Ferguson 1994):

(i) A straight-line interconnection of plants, each adding modules to the semi-finished product sent by the previous plant and passing it on to the successor. The product variety is limited, the material flow unidirectional and the decisions are infrequently made as to when to stop the line for switchover to another product type or how large the batch size should be. Mass production and continuous manufacturing are examples of this type. Batch sizes are large in this case.

(ii) The second case is when customization occurs in the later manufacturing stages. The production is for standard items which are customized to provide the variety either at 


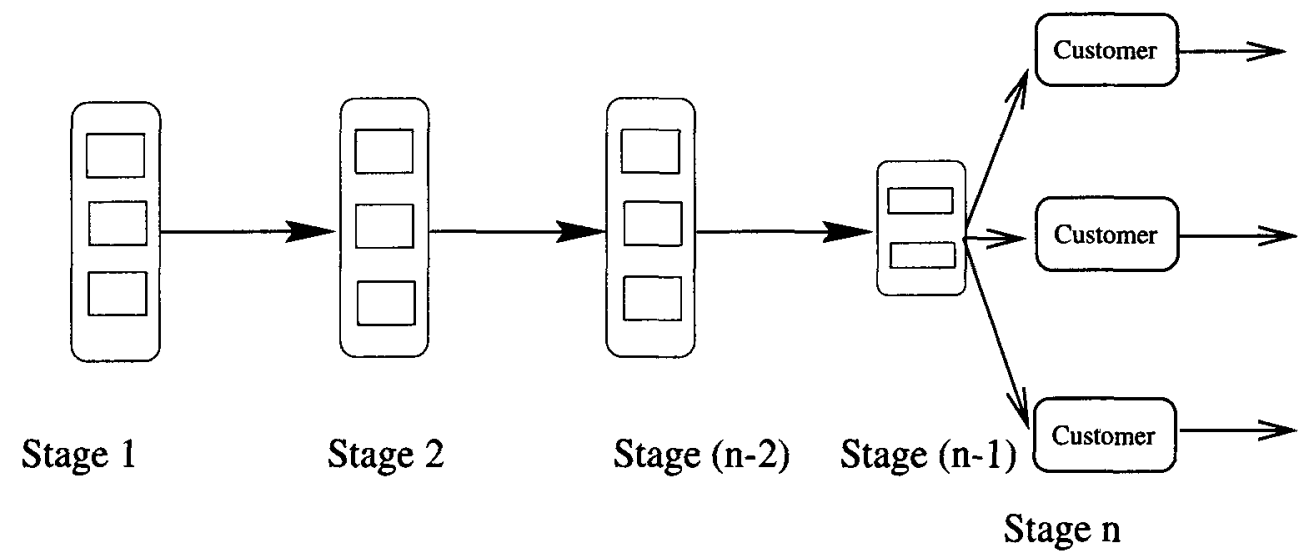

Figure 9. Product (manufacturing plant) structure with late customization.

the customer end or at a local manufacturing plant or distribution centre. The structure of the plant looks similar to the one shown in figure 9.

Personal computers, IC chips, disk drives, laser printers and other electronic equipment follow this pattern. Here a product variety can be obtained through dedicated plants to perform the last stages of manufacturing. Also, modular design of the product keeping in view the logistic costs will reduce the total logistic costs as well as help in effective supply chain management. The individual customer demands could be highly variable, but the total semi-finished product demand variability is low. Hence it makes lot of sense to maintain inventories at the subassembly level which are customized based on individual demands and thus maintain low lead times (Lee \& Feitzinger 1996).

The various stages of manufacturing could be dispersed across continents and transportation is often on the high seas. Thus the economic transportation batch size is larger than in closely located plants. This dictates that the production batch size of the predecessor plants also be high. Thus batch sizes and inventories are high and product variety is low in all the first $(n-1)$ stages. The final stage, however, has dedicated low volume plants.

In the plant structure shown in figure 9, uncertainties in customer demands and long transportation times are basically met through staged manufacturing plants with dedicated technology, inventories, and large-to-medium batch sizes. Supplier management, partnership with logistics agents, modular product designs are some of the enablers for good flexibility management in this case.

(iii) We consider the third case of plants where customization starts early in the production stages and which have a diverging architecture (see figure 10). Starting with a limited number of raw materials, a wide variety of finished products are produced. Such examples can be found in electro-mechanical systems such as motors, textiles, metal fabrication, and chemicals.

The enterprise is very complex from a managerial viewpoint. Several plants with similar manufacturing capabilities have to be managed, and have to maintain 


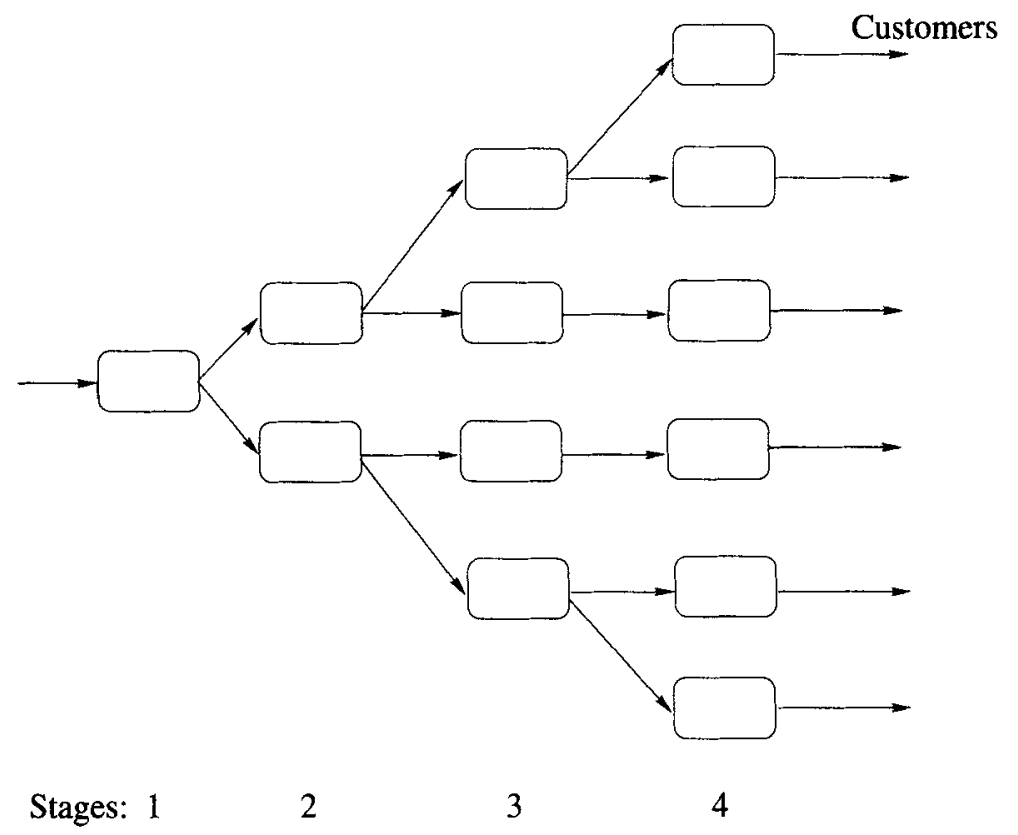

Figure 10. Product flow and manufacturing plant structure with early customization.

partnership relations with several suppliers, distributors, and customers. The plants could be staged or can be at central locations and made flexible using automated technologies. The batch sizes are typically low, and lead times are to be small. Low inventories are to be maintained for cost competitiveness. Integration using EDI and bar coding, and scheduling customer orders using point-of-sale information would increase the effectiveness of the supply chain. The mix flexibility for the supply chain is very high. Volume fluctuations are handled through large number of suppliers and quick feedback for point-of-sale information. The order has to travel through lots of organizations and the interfaces are generally not managed; instead high inventories are maintained.

(iv) The final architecture is assembly-oriented with converging architecture. One finds such patterns in the manufacture of aircraft and in construction. Numerous raw materials are transformed into sub-assemblies and finally into a huge assembly (see figure 11). Large number of mid-volume components are produced at various stages of manufacturing. Components are globally sourced from a variety of suppliers. The management is complex. Here again supplier management, flexible manufacturing, and information integration would enhance the enterprise's performance. Small batch sizes, sometimes one of a kind, and low inventories are typical here. The supply chain is definitely mix-flexible, for e.g., aircraft manufacturers like Boeing have wide-body, narrow-body aircraft and the 777's. The product mix gets smaller as the structure converges, high at the components level and low at the final assembly level. Scheduling to deliver products on-time is an important issue in both the construction and the aircraft industry. 


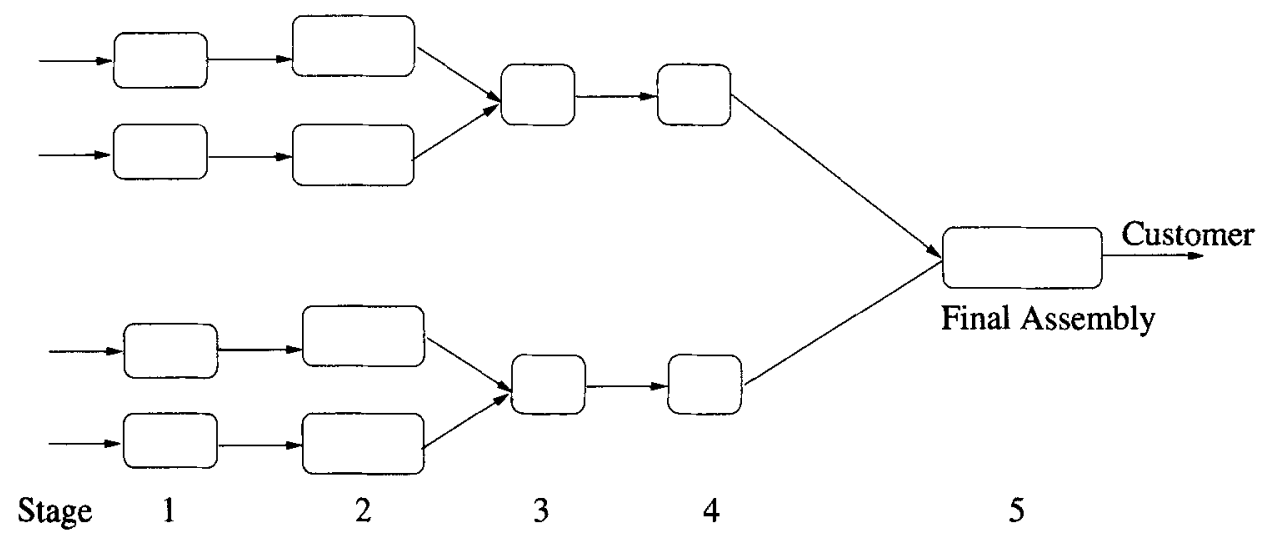

Figure 11. Converging product (manufacturing plant) structure.

We have described a few typical architectures and used these as vehicles to discuss the flexibility issue. Our intention here is to point out the fact that flexibility, as the final user sees it in terms of variety, can be obtained in several ways depending on the product structure.

\section{Conclusions}

In this paper, we attempted a complete definition of a manufacturing system as a set of integrated activities involving suppliers, production, distributors, customers, competition, logistics etc. and emphasized the need for coordination among these activities via management of end-to-end business processes. We also brought out the fact that a preliminary analysis of the uncertainties that a manufacturing system faces, and the subsequent design of the system for flexibility and also the design of control systems to reduce the effects of these uncertainties on system performance are essential for achieving sustainable competitive advantage. We defined the performance metrics for business processes.

We have defined flexibility of business processes and presented definitions and measures for important processes such as product development, supply-chain and order-to-delivery processes. Finally, the discussion presented here is equally valid for continuous and chemical manufacturing systems as well. Except for a manufacturing plant that has continuous dynamics, the rest of the system is identical to the one discussed here. Even in continuous processes, there is too much attention paid to the manufacturing process and less to logistics and the interface activities between various functions and organizations. Attractive gains can be made using IT and process management techniques in reducing the cycle time and improving quality in these processes.

We would like to acknowledge several colleagues for the time and effort they had spent in discussions and in refining the manuscript. Special thanks are due to Prof. Y Narahari, who spent enormous time in discussions on business processes, their management and performance analysis. 


\section{References}

Cohen M A, Lee H L 1988 Strategic analysis of integrated production distribution systems: models and methods. Oper. Res. 36: 216-228

Connors D, An C, Buckley S, Feigin G, Levas A, Nayak N, Petrakian R, Srinivasan R 1995 Dynamic modeling of re-engineering supply chains, IBM Research Report 19944

Corline D N, Essaides G 1993 Time-based competition. The Economic Intelligence Unit Research Report S-159

Davenport T H 1993 Process innovation (Cambridge, MA: Harvard Business School Press)

Hartley J 1993 Electronic date interchange, gateway to world class supply chain management. The Economic Intelligence Unit Research Report P-660

Kekre S, Srinivasan K 1990 Broader product line: a necessity to achieve success. Manage. Sci. 36: 1216-1231

Lee H L, Feitzinger E 1996 Product configuration and postponement for supply chain efficiency. Technical Report, Stanford University, Stanford, CA

Macbeth D K, Ferguson N 1994 Partnership sourcing: An integrated supply chain management approach (Pitman)

Macduffie J P, Sethuraman K, Fisher M L 1996 Product variety and manufacturing performance: evidence from international automotive assembly plant study. Manage. Sci. 42: 350-369

Milgrom P, Roberts J 1990 The economics of modern manufacturing: Technology, strategy and organization. Am. Econ. Rev. 80: 11-528

Prahlad C K, Hamel G 1990 The core competence of the corporation. Harvard Business Rev. May-June: 79-91

Sethi A K, Sethi S P 1990 Flexibility in manufacturing: A survey. Int. J. Flexible Manuf. Syst. 2: 289-328

Smith B 1993 Six-sigma design. IEEE Spectrum 30(9): 43-47

Srinivasan K, Kekre S, Mukhopadhyay T 1994 Impact of electronic data interchange technology on JIT shipments. Manage. Sci. 40: 000-000

Stalk G N Jr, Hout T M 1990 Competing against time (Free Press)

Suarez F F, Cusumano M A, Fine C H 1996 Flexibility and performance: A literature critique and strategic framework. Manage. Sci. 44: 223-240

Ulrich K T, Eppinger S D 1995 Product design and development (New York: McGraw-Hill)

Upton D M, McAfee A 1994 The management of flexibility. California Manage. Rev. Winter: 72-97

Upton D M, McAfee A 1995 What really makes factories flexible. Harvard Business Rev. JulyAugust: 74-84

Upton D M, McAfee A 1996 The real virtual factory. Harvard Business Rev. July-August: 123-133

Venkataraman N 1994 IT established business transition: From automation to business scope redefinition. Sloan Manage. Rev. Winter: 000-000

Viswanadham N, Narahari Y 1992 Performance modeling of automated manufacturing systems (Englewood Cliffs, NJ: Prentice-Hall)

Viswanadham N 1996 Competitive Manufacturing Enterprises. India 2010-Leadership through science and technology (Bangalore: Indian Academy of Sciences) (under preparation)

Wang E T G, Seidmann A 1995 Electronic date interchange: Competitive externalities and strategic implementation policies. Manage. Sci. 41:000-000

Williams J F 1981 Heuristic techniques for simultaneous scheduling of production and distribution in multi-echelon structures: Theory and empirical comparisons. Manage. Sci. 27: 000-000

Womack J P, Jones D T, Ross D 1990 The machine that changed the world (Harper Perennial) 